\title{
PREFIJOS, PREVERBIOS, PARTICULAS Y EL CONTINUO \\ LÉXICO-GRAMATICAL
}

\begin{abstract}
Resumen. Los phrasal verbs ingleses son considerados como característicos del grupo tipológico de las lenguas satellite-framed (Talmy, 1985), cuyo prototipo serían las lenguas germánicas. Sin embargo, si comparamos con las lenguas románicas, no sólo encontramos también este tipo de formación, sino que la función de su partícula es también muy similar a la atribuida generalmente a los prefijos, definidos a su vez de forma imprecisa. Partiendo del grado de fijación e idiomaticidad del espacio fraseológico, clasificamos las expresiones verbales en una escala, empezando por los verbos soporte, que serían el extremo limítrofe con la sintaxis, siguiendo con las locuciones verbales, los verbos sintagmáticos separables, los verbos sintagmáticos inseparables y los verbos compuestos, siendo estos últimos el extremo limítrofe con el léxico.
\end{abstract}

Palabras clave: preverbios, postverbios; prefijos, fraseología, phrasal verbs.

\section{Introducción}

Partiendo de que el elemento más básico de un evento es la expresión del desplazamiento en el espacio-tiempo, Talmy (1985) divide las lenguas del mundo en dos grandes tipos, dependiendo de que su codificación de la trayectoria esté dentro del propio verbo (verb-framed languages) o añadida en un "satélite", es decir, un elemento externo al verbo pero asociado a él (satellite-framed languages) (Talmy, 1991: 486). P. ej., comparando esp. entrar $\neq$ salir con rs. входить $\neq$ выходить, alm. hereinkommen $\neq$ herauskommen e ing. go in $\neq$ go out, las lenguas románicas corresponderían al primer tipo, mientras que las lenguas eslavas y germánicas pertenecen al segundo (cf. Kopecka, 2004: 114). El phrasal verb, al ser unión de un verbo y un elemento, generalmente de origen locativo-direccional pero que ya no es ni preposicion, ni adverbio (Kunin, 1996: 308-309), sería un representante por excelencia del tipo satellite framed.

\footnotetext{
* Universidad de Granada.
} 
Un ejemplo prototípico sería la construcción no metafórica: Pablo salió de la escuela corriendo, donde el español parte de un verbo específico de trayecto abstracto (salir = "movimiento hacia fuera"), y lo complementa con la manera concreta de desplazarse ("a pie y muy deprisa") en un complemento adverbial que puede a su vez ser un segundo verbo (corriendo). En cambio, lenguas eslavas y germánicas parten de una manera concreta de desplazarse (rs. бегать, pol. biegać, alm. rennen, ing. to run = "correr"), y la complementan indicando la trayectoria mediante una partícula direccional abstracta (el postverbio out o el preverbio вы: "hacia fuera"). La precisión de este elemento directivo-espacial puede ser mayor o menor. Así en esloveno el verbo skočiti ("saltar") se distingue del verbo preskočiti "saltar por encima" y del verbo vskočiti "saltar dentro" (Žaucer, 2002: 7), pero es el valor espacial de las preposiciones convertidas en prefijos el único responsable de estas diferencias léxicas (slvn. prek "encima de"; $v$ "dentro de"). Esta tabla ilustra un reparto de las lenguas que coincide con este criterio, con las lenguas románicas en la misma columna (verb-framed), opuestas a las eslavas y germánicas que se juntan en la otra columna (satellite-framed):

Tabla 1. Ejemplo de la oposición verb-framed vs. satellite-framed

\begin{tabular}{|c|c|}
\hline TRAYECTO MEDIANTE VERBO & $\begin{array}{c}\text { TRAYECTO MEDIANTE } \\
\text { "SATÉLITE" }\end{array}$ \\
\hline esp. Pablo salió de la escuela corriendo & ing. Paul ran out of the school \\
\hline fr. Paul est sorti de l'école en courant & alm. Paul rannte aus der Schule \\
\hline pt. o Pablo saiu da escola correndo & rs. Павел выбежал из школы \\
\hline it. Paolo è uscito correndo dalla scuola & pol. Pawet wybiegł ze szkoty \\
\hline cat. en Pau ha sortit de l'escola corrent & chc. Pavel vyběhl ze školy \\
\hline rum. Pavel a ieșit fugind din școală & ucr. Павдо вибігі із шкоди \\
\hline
\end{tabular}

Fuente: elaboración propia.

Sin embargo, el hecho de que, para expresar el desplazamiento, un procedimiento analítico pueda cumplir la misma función que un procedimiento sintético no descarta la posibilidad de que una misma lengua use ambos mecanismos (cf. Kopecka, 2004; Michot et al., 2015; Pamies, 2018b; 2019). Por otra parte, tampoco hay nada que -a prioriimpida que dichos mecanismos se apliquen a verbos que no son de desplazamiento. Al fin y al cabo, el movimiento es uno de los dominios fuente más productivos del lenguaje figurado, y nada garantiza tampoco -a priori- que los desplazamientos metafóricos tengan el mismo régimen morfosintáctico que los literales. 


\section{Preverbios, postverbios y prefijos}

Un preverbio es un elemento que se adjunta a un verbo pero conservando una relativa autonomía que le permite realizar modificaciones semánticas, dando lugar a verbos nuevos (Buridant, 1995: 292). Formalmente, se opone al postverbio de los phrasal verbs, que cumple la misma función pero en el orden sintático inverso. Así p. ej., en inglés, la partícula adverbial locativa down es un preverbio en download ("descargar") y un postverbio en feel down ("estar desmoralizado"), en ambos casos produce una función oracional única y un sentido global indivisible. Sin embargo, aunque sea en proporciones distintas, preverbios y postverbios pueden coexistir en una misma lengua (give $u p$ vs. uphold). No sólo el inglés tiene postverbios, los encontramos también en los verbos separables alemanes, así como en los verbi sintagmatici del italiano

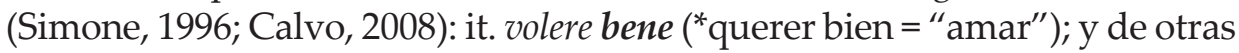
lenguas neolatinas: esp. venirse abajo ("hundirse" / "desmoralizarse"); cat. fer-se enllà ("hacerse allà = "alejarse"); pt. estar por dentro (*estar por dentro = "estar bien informado"); fr. rentrer dedans (*entrar dentro = "atropellar / chocar / atacar") (Pamies, 2019). También se corresponden a esta definición expresiones rusas como идти налево (*ir a + la + izquierda "cometer adulterio") (Pamies; Pazos \& Mironesko, 2019).

Es posible incluso que, con el mismo verbo y el mismo sentido, un preverbio sea convertible en postverbio, dependiendo de su conjugación. P. ej., alm. mitkommen $\rightarrow$ kommst mit mir ("acompáñame"); austrinken ("fuera + beber = "beber totalmente" $) \rightarrow$ trink das Glas aus "acábate el vaso" (Pamies y Pazos, 2018); fr. bien vouloir ("bien querer = "aceptar") $\rightarrow$ je veux bien ("acepto"). La conmutabilidad entre preverbio y postverbio, demuestra su equivalencia semántico-funcional, y se observa incluso en inglés, p. ej., entre break up y upbreak ("descomponer"), o entre hold up y uphold ("resistir"). En cambio, el prefijo (propiamente dicho) no es un lexema, porque no existe por sí solo fuera de las palabras que lo albergan, y porque es un gramema cuya presencia o ausencia corresponde a reglas morfosintácticas (Pamies, 2018b; 2019).

\section{Aspectualidad}

Las lenguas eslavas distinguen de manera sistemática entre el aspecto imperfectivo y el perfectivo por medio de unos pares mínimos simétricos en que un prefijo produce la versión perfectiva del mismo 
verbo (p. ej., rs. играть "jugar" ₹ сыграть “haber jugado"). En este caso son prefijos porque corresponden a una regla gramatical: los verbos son imperfectivos por defecto y la prefijación los convierte en perfectivos, nunca al revés. Un verbo con sentido nuevo sólo puede derivarse de uno perfectivo, y de allí puede surgir otro verbo imperfectivo añadiendo entonces un sufijo (Fougeron, 1995; Cygal-Krupa, 1995) ${ }^{1}$. Aunque los eslavistas usen a menudo prefijo y preverbio como sinónimos, dividen luego los "prefijos" en dos subclases, los lexicales (que implican un nuevo significado verbal) y los gramaticales, también llamados deslexicalizados o incluso "vacíos", que son los que, exclusivamente, añaden el aspecto perfectivo a un verbo originalmente imperfectivo (Fougeron, 1995: 256). Un test complementario para distinguirlos entre sí consiste en que si la partícula inicial es un prefijo aspectual: la traducción española no cambia de verbo sino de conjugación ( $\alpha$ : gramema) y, en cambio, si la particula es un preverbio, la traducción no cambia de conjugación sino de verbo ( $\beta$. lexema):

$\alpha$. rs. читать $\neq$ прочитать // pol. czytać $\neq$ przeczytać $\rightarrow$ esp. leer $\neq$ haber leído;

$\beta$. rs. играть $\neq$ выиграть // pol. grać $\neq$ wygrać $\rightarrow$ esp. jugar $\neq$ ganar;

Hay otros aspectos, introducidos por prefijos de base preposicional, pero no aplican una regla general sino que se memorizan como verbos lexicalmente distintos (Fougeron, 1995: 267). P. ej., en polaco, la preposición $z$ ("desde") es prefijo incoativo en zsinieć (“desde + palidecer = "ponerse pálido") y po ("después") lo es en pokochać ( "después + amar = "enamorarse"), mientras que la preposición do ("hasta") hace de prefijo terminativo en dopić ("hasta + beber $=$ "beber hasta el final"), dośpiewać ("hasta + cantar = "cantar hasta el final" [una melodía]), dolecieć ("hasta + volar = "llegar" (volando), dorysować (*hasta + dibujar = "terminar un dibujo") (Cygal-Krupa, 1995: 270-274). En ruso, la preposición по ("por" / "a lo largo de") hace de prefijo incoativo еп пойти $($ * por $+\mathrm{ir}=$ "irse" $)$ о побегать $($ *por + correr $=$ "echar a correr"); en cambio, la preposición из ("desde") hace de prefijo terminativo en измылить $\left({ }^{*}\right.$ desde + enjabonar $=$ "gastar el jabón hasta el final") (Fougeron, 1995: 258-259).

Las lenguas románicas y germánicas a menudo pueden expresar de manera reglada la oposición entre perfectivo e imperfectivo, siendo el ejemplo más obvio el de la conjugación (p. ej., esp. comía $\neq$ ha comido; fr. il

${ }^{1}$ Dejamos aquí de lado las escasas excepciones, entre ellas los verbos de estado (p. ej., rs. жить; pol. $\dot{z} y c ́$ = "vivir") y los préstamos de origen francés, como rs. резервировать = "reservar"; pol. replikować = "replicar"; slvn. reorganizati "reorganizar" (Fougeron, 1995; Cygal-Krupa, 1995; Žaucer, 2002). 
mangeait $\neq$ il a mangé; ing. he was eating $\neq$ he has eaten; alm. er aß $\neq$ er hat gegessen). También se corresponden a algo que el inglés hace mediante postverbios, p. ej., clean $\neq$ clean up; drink $\neq$ drink out. El alemán también (er trank (das Bier) $\neq$ er trank<das Bier>aus).

Pero, incluso en estas lenguas, la aspectualidad no se limita ni a estos aspectos ni a estos marcadores. Los ya mencionados incoativo y terminativo pueden tener varias otras formas de expresarse. Proyectando metafóricamente el espacio sobre el tiempo, el Aktionsart télico puede expresar el paso del punto inicial al punto final (p. ej., entrar en la casa), mientras que el atélico representa el trayecto del desplazamiento (p. ej. caminar hasta la casa), y en ambos casos la marca de esta dicotomía estaría en la preposición. (cf. Kopecka, 2004: 112). En las lenguas románicas, la aspectualidad incoativa puede estar lexicalmente marcada por adjunción de preverbios de origen espacial (esp. enloquecer, it. impazzire), similarmente a lo que hemos visto en los verbos de desplazamiento de las lenguas eslavas (пойти). Lo mismo ocurre con el aspecto terminativo: alm. austrinken ("fuera + beber) = "beber hasta el final"), una solución casi idéntica a la del polaco (dopić). También hay parejas de preverbios espaciales que oponen estos dos aspectos en un mismo verbo, como en fr. emménager [incoativo] ("empezar a vivir en una nueva casa") vs. déménager [terminativo] ("dejar de vivir en una casa para irse a otra"): el movimiento espacial figurado (entrada vs. salida) remite aquí a las fases iniciales y finales de un mismo proceso. Ello coincide así con los preverbios eslavos y germánicos como rs. включить / pol. włączyć (*en + conectar $=$ "encender") vs. выкдючить / wyłączyć ("fuera + conectar = "apagar"); y también con los del alemán anschalten $\neq$ ausschalten y que en inglés corresponden a postverbios (switch on $\neq$ switch off). Es decir, existen pares mínimos con Aktionsart incoativo o terminativo por medio de una metáfora gramatical que proyecta cambios espaciales antonómicos (entrada $\neq$ salida) sobre las fases temporales internas de un proceso.

Tanto en las lenguas eslavas (cf. Cygal-Krupa, 1995: 278) como románicas, ni es siempre el mismo preverbio el que marca la incoatividad, ni existe un preverbio que sólo pueda expresar este aspecto, Tampoco el preverbio es la única marca posible ${ }^{2}$. En francés, el preverbio espacial en- permite formar el incoativo s'envoler $\left({ }^{*}\right.$ se + en + volar = "echar a volar"), y algo parecido encontramos en catalán, alemán y ruso (en volarse *en + volar + se / wegfliegen *lejos + volar / улететь * ${ }^{*}$ cerca + volar $=$

\footnotetext{
2 Además, hay algunos verbos que, por su propia semántica, sólo designan una fase de un proceso, ya sea la inicial, o la final, excluyendo las fases intermedias. P. ej., esp. ensillar/desensillar [un caballo] aunque no exista el verbo *sillar.
} 
"echar a volar"). En inglés se hace con un postverbio (fly off *volar fuera), y también en italiano (volare via * volar lejos). En este caso concreto, el español no dispone de este verbo sintagmático y recurre a perifrasis incoativas (salir volando / echar a volar), o a colocaciones lexicalizadas levantar el vuelo / alzar el vuelo. En ruso, el preverbio (в "en") es incoativo еn вдюбиться (*en + amar + se $=$ "enamorarse") у lexical en всадить $\left({ }^{*}\right.$ en + sentar $=$ "clavar" $)$.

La preverbación incoativa es por tanto más cercana a la composición que a la derivación, puesto que el sentido global del verbo resultante no es predecible, ni su formación guiada por una regla estable (Pamies, 2018b; 2019). En estas construcciones, el reparto de lenguas ya no corresponde a la tipología de Talmy ( $c f$. tabla 1): lenguas de la misma familia ya no estarían necesariamente en la misma columna, puesto que la configuración puede cambiar de un verbo a otro.

\section{Composición vs. derivación}

Martinet (1960) incluyó entre los sintemas cualquier tipo de amalgama entre monemas, equiparando así composición con derivación, pero su grado de lexicalización es muy heterogéneo. De hecho, podemos incluso distinguir varios grados dentro de lo que la morfología llama prefijos, pues proceden de preposiciones y / o adverbios de los cuales algunos pueden haber mantenido parte de su autonomía original y, por lo tanto, se comportan como preverbios. Los "verdaderos" prefijos verbales forman series productivas y analógicas: los hablantes / oyentes pueden presuponer que releer es a leer lo que reabrir es a abrir y lo que retwitear es a twitear. Los preverbios y postverbios no se comportan de esta manera; las modificaciones semánticas que provocan no son ni sistemáticas ni predecibles, sino léxicamente específicas. P. ej., Los preverbios sobre y entre no aportan el mismo significado en sobrecargar, sobrecoger, sobreentender, entrecortar, entreabrir, entrever y entretener. Tampoco los postverbios con y atrás aportan la misma modificación en quedar con ("darse cita") que en contar con ("confiar").

Aunque preverbio y prefijo sean de origen preposicional o adverbial, el preverbio sigue siendo un "satélite" espacial mientras que el prefijo se ha amalgamado totalmente al verbo: los hablantes ya no relacionan semánticamente entre sí suponer, imponer, exponer y componer, porque -comunicativamente- no tiene sentido distinguir "partes" en ellos. 
Según este criterio, la partícula espacial sobre se comporta como un prefijo en verbos derivados regulares predecibles, como sobrecargar, sobrevalorar, sobreestimar, sobreactuar, sobrealimentar ("en exceso"), pero se comporta como preverbio en compuestos idiomáticos, como sobrecoger, sobrellevar, sobreentender o sobreseer. A diferencia de los prefijos, los preverbios y post-verbos son procedimientos idiomáticos, mientras que los prefijos son instrumentos gramaticales. Un criterio complementario es que, a diferencia del prefijo, el preverbio existe por sí mismo como palabra (Pamies, 2019). Verbos como reprobar, prometer o disparar son derivados prefijados, porquelas partículas re-, pro-y dis- no existen solas. Este criterio se hace aún más evidente cuando el verbo tampoco existe solo, como en producir, traducir, inducir, deducir. No pueden ser compuestos porque no hay palabras reconocibles en su interior ${ }^{3}$.

En cambio, los verbos con preverbio como entretener o sobrecoger son compuestos porque tienen dos lexemas, y su fijación e idiomaticidad internas los coloca en la esfera de lo fraseológico, aunque se escriban como si fueran palabras (Pamies, 2007, 2017). Esta distinción entre preverbio y prefijo es especialmente relevante, porque coincide con la frontera extrema entre palabras y frasemas (Pamies, 2019), aunque la grafía lo oculte.

Por lo tanto, lo que la morfología llama tradicionalmente prefijos sería una mezcla que abarca y solapa grados heterogéneos de lexicalización: [1] preverbio en un verbo compuesto (sobreentender; entrever), [2] prefijo -propiamente dicho- de un derivado (recaer, desbloquear), [3] residuo etimológico en un verbo simple cuyo radical ya no existe por sí solo (repetir, producir). Para ser un preverbio o un postverbio, una partícula debe existir como palabra, aunque nada impide que preposiciones existentes sean prefijos, si son suficientemente regulares y productivas, o si el verbo en sí no existe solo.

${ }^{3}$ Las aparentes excepciones se deben a la pérdida de autonomía del verbo base. Así, por deformación fonética desaparecieron del español los verbos latinos ducere "dirigir", petere "buscar", premere "empujar", por lo cual la composición interna dejó de ser transparente en verbos como reducir, conducir, deducir, repetir, competir, reprimir, deprimir, comprimir. Etimológicamente, son compuestos, pero, sincrónicamente, son verbos simples. En cambio, otros verbos como releer, representar, recalcular, reformar, conformar, condecorar, conceder, condonar, siguen siendo analizables por los hablantes como derivados, cuya regla de prefijación sigue siendo productiva (reescanear, redimensionar; codirigir, cofinanciar, configurar, reconfigurar, retwitear), porque su radical sigue existiendo como palabra (escanear, dirigir, financiar, dirigir, figurar, twitear). Incluso el valor etimológicamente locativo que todavía se percibe en el prefijo ex- de cultismos como extraer, excavar o exportar, ya resulta opaco en muchos otros verbos de idéntica formación. (explicar, extender, exaltar, exacerbar, examinar, exceder, excitar, etc.). 
En las lenguas eslavas, la frontera entre preverbio y prefijo puede resultar más difusa, ya que, a primera vista, podría parecer que, como las partículas rs. вы- y pol. $v y$ - significan algo pero no existen como palabras (necesitan amalgamarse a un verbo de movimiento, como en rs. выходить \& pol. wychodzić), éstas serían prefijos, mientras que в- / v-, ("en" / "dentro $\left.\mathrm{de}^{\prime \prime}\right)$, al existir también como preposiciones serían automáticamente preverbios (rs. входить / pol. wchodzić). Para evitar tal exageración hay que matizar con un segundo criterio: el de la productividad sistemática. Hay una regla general, que permite deducir de forma estable que un verbo de desplazamiento con anteposición de вы / vy señala hacia fuera y, con la de в / $v$ señala hacia dentro, por lo cual no se trata de una casuística impredecible sino de un fenómeno productivo regular, gramaticalizado ante verbos de movimiento: выводить ("fuera + dirigir = "sacar"), выезжать ("fuera + conducir = "irse [lejos]"), выносить ( fuera + llevar = "llevarse"), вылетать ("fuera + volar = "salir volando"), etc. Por ello tanto вы / vy como в / $v$ se pueden considerar como prefijos cuando se anteponen a verbos de movimiento literal, aunque no así en los figurados.

Los verbos prefijados son palabras mientras que los verbos con postverbios y preverbios son compuestos, $y$, por tanto, fraseologismos (por ser multilexemáticos, fijados e idiomáticos). Habría pues dos partículas " $\mathrm{B}$ " homónimas en ruso: el prefijo of входи́ть (literal y regular: *dentro+andar = "entrar") y el preverbio de влюбиться (idiomático e impredecible: *dentro+amar+se = "enamorarse"), siendo este último un frasema, pese a su grafía. Tanto en lo funcional como en lo semántico, esta diferencia entre preverbio y prefijo coincide en los verbos la frontera entre palabra y frasema (Pamies, 2018b; 2019; Pamies y Pazos, 2018), que podemos situar de esta manera a lo largo del continuo léxico-gramatical de la expresión verbal:

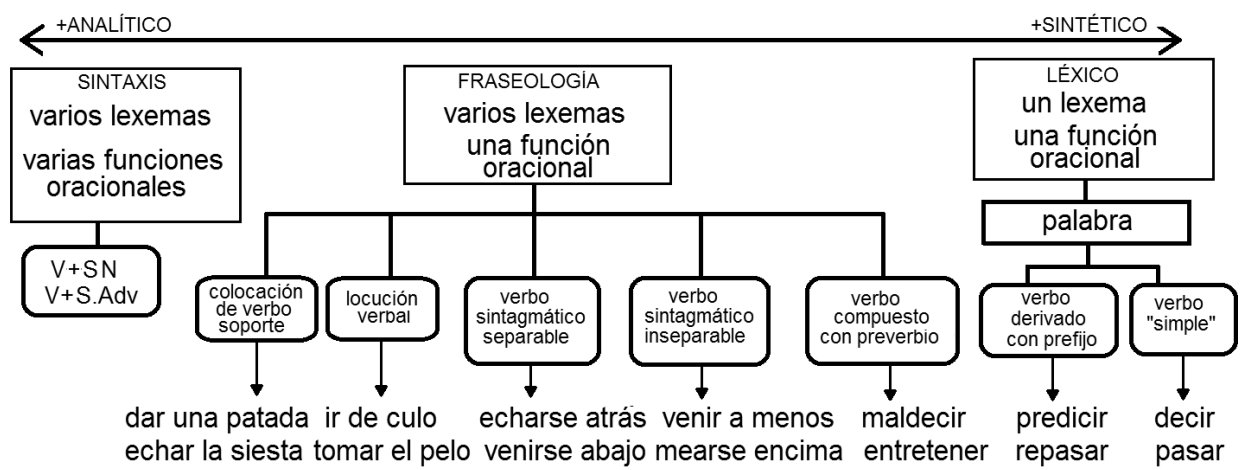

Gráfico 1. El continuo léxico-gramatical de la expresión verbal

Fuente: adaptado de Pamies y Pazos, 2018; Pamies, 2019. 


\section{Desplazamiento literal y figurado}

El desplazamiento puede ser metafórico, y de maneras muy variadas. P. ej., en virtud de una archimetáfora compartida por muchas lenguas europeas, la incoatividad de ciertos estados mentales (SUEÑo, EMBRIAGUEZ, AMOR, LOCURA, etc.) es conceptualizada como UN movimiento hacia dentro (Iñesta y Pamies, 2002). La tipología de Talmy debería hacernos esperar que las lenguas románicas representasen este imaginario trayecto con un verbo direccional (como efectivamente ocurre en entrar en trance o entrar en coma) y que, en cambio, las lenguas germánicas y eslavas lo hicieran siempre con un verbo "concreto" unido a una particula direccional (como efectivamente ocurre en. pol. zakochać się "enamorarse" о rs. напиться "еmborracharse"; rs. уснуть / заснуть "quedarse dormido"). Pero ese razonamiento sólo funciona realmente para el desplazamiento "literal". Las lenguas europeas a menudo simbolizan como "desplazamiento orientado" el inicio de un estado mental, p. ej., con partículas locativas, se focaliza el inicio de ciertos fenómenos mentales en enamorarse, asustarse, entristecerse, en cuyo caso, en contra de lo esperable, un "satélite" aparece en español (enloquecer) mientras que la direccionalidad recae en el verbo en la locución rusa (cxodumb c yмa *salir de espíritu = "volverse loco").

Al comparar algunas de estas formas incoativas de movimiento figurado en varias lenguas, comprobamos en seguida que su modelo metafórico no es predecible, ni de una acción a otra, ni de una familia lingüística a otra. Para el sueño o la prisa, encontramos un preverbio en francés (s'endormir *se + en + dormir) pero no en español, donde hay una colocación (quedarse dormido). Ocurre lo inverso con el AMOR y la LOCURA, donde el español sí usa preverbio (enamorarse), pero el francés recurre a colocaciones (tomber amoureux * caer amoroso). Cuando el desplazamiento es sólo figurado, el reparto lingüistico resultante se aleja por completo de lo que correspondía a la dicotomía verb-framed vs. satellite framed para el movimiento literal (tabla 2), incuso tiende a invertirse. Por ejemplo, para la incoatividad de la embriaguez, no sólo tenemos una distribución diferente que para el movimiento literal (tabla 1), sino que tampoco coincide con la del amor, el sueño o la locura. 
Tabla 2. Ejemplos de la oposición entre incoatividad sintáctica y morfológica

\begin{tabular}{|c|c|}
\hline $\begin{array}{c}\text { INCOATIVIDAD COMO } \\
\text { TRAYECTO METAFÓRICO } \\
\text { MEDIANTE VERBO, PERÍFRASIS } \\
\text { O FRASEMA }\end{array}$ & $\begin{array}{c}\text { INCOATIVIDAD } \\
\text { COMO TRAYECTO METAFÓRICO } \\
\text { MEDIANTE PARTÍCULA }\end{array}$ \\
\hline \multicolumn{2}{|c|}{ EMBRIAGUEZ } \\
\hline $\begin{array}{l}\text { it. ubbriaccarsi. } \\
\text { ing. get drunk } \\
\text { alm. sich betrinken } \\
\text { svn. se piti } \\
\text { cro. se piti }\end{array}$ & $\begin{array}{l}\text { esp. emborracharse } \\
\text { fr. s'ennivrer } \\
\text { pt. se embebedar / se inebriar } \\
\text { pol. ирić się } \\
\text { rs. напиться }\end{array}$ \\
\hline \multicolumn{2}{|c|}{ AMOR } \\
\hline $\begin{array}{l}\text { fr. tomber amoureux } \\
\text { ing. to fall in love } \\
\text { alm. sich verlieben }\end{array}$ & $\begin{array}{l}\text { esp. enamorarse } \\
\text { pt. se apaixonar } \\
\text { it. innamorarsi } \\
\text { rum. se îndrăgostească } \\
\text { pol. pokochać / zakochać się } \\
\text { rs. вдюбиться }\end{array}$ \\
\hline \multicolumn{2}{|c|}{ SUEÑO } \\
\hline $\begin{array}{l}\text { esp. quedarse dormido } \\
\text { / quedarse frito } \\
\text { ing. fall asleep / pass into sleep }\end{array}$ & $\begin{array}{l}\text { alm. einschlafen } \\
\text { fr. s'endormir } \\
\text { it. addormentarsi } \\
\text { pt. adormecer } \\
\text { pol. zasnać } \\
\text { rs. уснуть / заснуть }\end{array}$ \\
\hline \multicolumn{2}{|c|}{ LOCURA } \\
\hline $\begin{array}{l}\text { fr. devenir fou } \\
\text { ing. get crazy / go nuts } \\
\text { rs. сходить с ума }\end{array}$ & $\begin{array}{l}\text { esp. enloquecer } \\
\text { pt. endoidecer } \\
\text { it. impazzire } \\
\text { alm. zuflippen } \\
\text { pol. oszaleć / zwariować }\end{array}$ \\
\hline
\end{tabular}

Fuente: elaboración propia.

\section{Conclusiones provisionales}

A) En el continuo léxico-gramatical, la fraseología ocupa todo el espacio que separa la sintaxis del léxico, "invadiendo" zonas tradicionalmente atribuidas a las estructuras sintácticas (colocación de verbo soporte y verbos sintagmáticos) o a las palabras (verbos compuestos). Dado que todas estas construcciones cumplen con todos los rasgos definitorios de 
la unidad fraseológica (con diferentes grados de fijación y lexicalización), algunas fronteras metalingüísticas deben reconsiderarse.

B) La oposición tipológica entre las lenguas verb-framed y satellite-framed (basada en la conceptualización del movimiento) es más cuantitativa que cualitativa, ya que las lenguas germánicas eslavas y románicas disponen de los mismos modelos. Lo que difiere en cada lengua son sus proporciones y su frecuencia de uso. Además, la selección de cada mecanismo también suele cambiar cuando el movimiento es sólo metafórico.

\section{Bibliografía}

BURIDANT, C. (1995). «Les préverbes en ancien français», en A. ROUSSEAU (ed.), Les préverbes dans les langues d'Europe. Introduction à l'étude de la préverbation. Lille: Presses du Septentrion, 287-323.

CALVO RIGUAL, C. (2008). «I verbi sintagmatici italiani, con appunti contrastivi con lo spagnolo e il catalano», en C. GONZÁLEZ ROYO y P. MOGORRÓN (eds.), Estudios y análisis de fraseología contrastiva. Alicante: Universidad, 47-66.

ČERMÁK, F. (1998). «La identificación de las expresiones idiomáticas», en J. d. D. LUQUE DURÁN y A. PAMIES BERTRÁN (eds.), Léxico y fraseología. Granada: Método, 1-18.

ČERMÁK, F. (2007). Frazeologie a idiomatika česká a obecná: Czech and General Phraseology. Praha: Karolinum.

CYGAL-KRUPA, Z. (1995). «Les préverbes en polonais», en A. ROUSSEAU (ed.), Les préverbes dans les langues d'Europe. Introduction à l'étude de la préverbation. Lille: Presses du Septentrion, 269-283.

FOUGERON, I. (1995). «Préfixe et aspect en russe contemporain», en A. ROUSSEAU (ed), Les préverbes dans les langues d'Europe. Introduction à l'étude de la préverbation. Lille: Presses du Septentrion, 224-267.

IÑESTA, E. M. y PAMIES, A. (2002). Fraseología y metáfora. Granada: Método.

KOPECKA, A. (2004). Étude typologique de l'expression de l'espace: localisation et déplacement en français et en polonais. Thèse doctorale. Lyon: Université Lumière Lyon 2.

KUNIN, A. V. (1996). Курс современной английской фразеологии. Дубна: Феникс+. MARTINET, A. (1960). Éléments de linguistique générale. Paris: Colin [rééd. 1967].

MICHOT, M.-E., GOLDSCHMITT, S. y PIERRARD, M. (2015). «Il saute dehors / Il grimpe dessus: particules adverbales de trajectoire en français L1 et L2», Pratiques: Linguistique, littérature, didactique, 167-168 [en línea] <http://pratiques.revues.org/2773> (DOI: 10.4000/pratiques.2773), fecha de consulta: 10 de agosto de 2018.

PAMIES, A. (2007). «De la idiomaticidad y sus paradojas», en G. CONDE (ed.), Nouveaux apports à létude des expressions figées. Cortil-Wodon: InterCommunications, 173-204. 
PAMIES, A. (2014a). «Provérbios fitonímicos e plantas proverbiais», en S. SILVA (ed.), Fraseologia \& Cia: entabulando diálogos reflexivos, vol. II, Campinas (Brasil): Pontes, 79-104.

PAMIES, A. (2014b). «A metáfora gramatical e as fronteiras (internas e externas) da fraseologia», Revista de Letras, 33/1 (Fortaleza: UFC), 51-77.

PAMIES, A. (2016). «Metafora grammaticale e metafora lessicale: implicazioni teoriche per la fraseologia», en E. DAL MASO y C. NAVARRO (eds.), Gutta cavat lapidem. Indagini fraseologiche e paremiologiche. Mantova: Universitas Studiorum, 87-120.

PAMIES, A. (2017). «Grammatical metaphor and functional idiomaticity». Yearbook of Phraseology, 8 (1), 69-104.

PAMIES, A. (2018a). «Les concepts d'unité et de construction en phraséologie», en O. SOUTET, S. MEJRI y I. SFAR (eds.), La phraséologie: Théories et applications. Paris: Champion, 59-79.

PAMIES, A. (2018b). «Phrasal verbs, idiomaticity and the fixedness continuum». International Conference Europhras 2018. Białystok, 10-12 sept. 2018 [text forecoming].

PAMIES, A. (2019). «El verbo sintagmático en las lenguas románicas» [en prensa].

PAMIES, A. y PAZOS, J. M. (2018). «Acerca del 'phrasal verb' en español y alemán», XIII Congreso Internacional de Lingüística General. Universidad de Vigo: 13-15 junio 2018 [en prensa].

PAMIES, A., PAZOS, J. M. y MIRONESKO, E. (2019). «Los verbos compuestos ¿combinaciones sintácticas, frasemas o palabras?». Congreso internacional Europhras: modelos productivos en fraseología. Univ. Santiago de Compostela: 24-25 enero 2019 [en prensa].

ROUSSEAU, A. (ed.) (1995). Les préverbes dans les langues d'Europe. Introduction à l'étude de la préverbation. Lille: Presses du Septentrion.

SIMONE, R. (1996). «Esistono verbi sintagmatici in italiano?», Cuadernos de Filología Italiana, 3, 47-61.

TALMY, L. (1985). «Lexicalization patterns: semantic structure in lexical forms», en T. SHOPEN (ed.), Language typology and syntactic description, Volume III, Grammatical categories and the lexicon. Cambridge: Cambridge University Press, 57-149.

TALMY, L. (1991). «Path to realization: A typology of Event Conflation», en L. A. SUTTON, C. JOHNSON y R. SHIELDS (eds.), Proceedings of the Seventeenth Annual Meeting of the Berkeley Linguistics Society. Berkeley: Linguistic Society, 480-510.

ŽAUCER, R. (2002). The Role of Verbal Prefixes in Slavic: Evidence from Slovenian Locative Denominal Verbs. Master Degree Thesis. Ottawa: University of Ottawa. 